\title{
Bhikhu PAREKH, Gurharpal SINGH, Steven VERTOVEC (éds), Culture and economy in the Indian diaspora
}

Aurélie Varrel

\section{(2) OpenEdition}

Journals

Édition électronique

URL : https://journals.openedition.org/remi/4097

DOI : 10.4000/remi.4097

ISSN : $1777-5418$

Éditeur

Université de Poitiers

Édition imprimée

Date de publication : 1 juillet 2006

Pagination : 179-180

ISBN : 2-911627-42-3

ISSN : 0765-0752

Référence électronique

Aurélie Varrel, « Bhikhu PAREKH, Gurharpal SINGH, Steven VERTOVEC (éds), Culture and economy in the Indian diaspora ", Revue européenne des migrations internationales [En ligne], vol. 22 - n² | 2006, mis en ligne le 27 novembre 2008, consulté le 15 avril 2022. URL : http://journals.openedition.org/remi/ 4097 ; DOI : https://doi.org/10.4000/remi.4097

Ce document a été généré automatiquement le 15 avril 2022.

(c) Université de Poitiers 


\title{
Bhikhu PAREKH, Gurharpal SINGH, Steven VERTOVEC (éds), Culture and economy in the Indian diaspora
}

\author{
Aurélie Varrel
}

\section{RÉFÉRENCE}

Bhikhu PAREKH, Gurharpal SINGH, Steven VERTOVEC (éds), Culture and economy in the Indian diaspora, Londres, New York, Delhi, Routledge, 2003, 227 p. (Routledge Research in transnationalism Series), ISBN : 0415270057.

1 Les publications sur la diaspora indienne (on parle en général indifféremment, notamment dans le titre de cet ouvrage, de diaspora indienne ou de diaspora sudasiatique, le second terme tenant compte de la Partition de 1947) se multiplient depuis le début des années quatre-vingt-dix, en une production diversifiée et en constante augmentation. Le développement de cette niche éditoriale tranche avec la littérature jusque-là disponible, assez limitée quantitativement et thématiquement, à dominante historique. Il reflète un faisceau d'évolutions, que l'on pourrait résumer comme la (re)découverte de la diaspora indienne, inscrites sur des plans et à des échelles différents : sur le plan de la recherche (comme pour d'autres groupes en migration); sur le plan éditorial, la diaspora indienne étant considérée désormais à la fois comme un sujet et comme un marché porteurs par les maisons d'éditions anglophones; à l'échelle du monde politique indien enfin, où les années quatre-vingt-dix ont marqué un retournement en faveur des immigrés et ressortissants étrangers d'origine indienne, délibérément ignorés depuis l'Indépendance.

2 On peut distinguer au sein de cette production deux grandes catégories d'ouvrages. D'une part se trouve un corpus de monographies par pays ou aires géographiques d'immigration. D'autre part la masse des actes de colloques ou séminaires réunit dans des ouvrages collectifs des études de cas assez précises, mais qui donnent souvent le 
sentiment d'assemblages de travaux géographiquement et méthodologiquement fort différents, et de qualité disparate.

Culture and ecomomy in the Indian diaspora appartient à la deuxième catégorie, avec pour origine un séminaire organisé à New Delhi en avril 2000 à l'initiative du Centre for Indian Studies de l'Université de Hull et de feu l'équipe Transcomm d'Oxford. L'ouvrage souffre des problèmes inhérents à la forme des actes, ce que reflète son titre même. Il reprend en effet celui du séminaire, général sinon vague, ce qui est en soi une indication de la diversité des contributions, dont quelques-unes semblent vraiment en marge, soit de la perspective de réflexive affichée par l'introduction, soit du niveau du reste des contributions (chapitres 2, 3, 5, 9).

4 L'introduction rédigée par Gurharpal Singh prend d'emblée ses distances par rapport à ce titre en affichant une volonté de jeter « les bases d'une sociologie culturelle et politique de la diaspora indienne ", et précède les éventuelles critiques sur le caractère "éclectique " des contributions au nom de la richesse du contenu : le programme de l'ouvrage serait donc d'une portée autre que de simples actes. Elle balaie les questions-clés relatives à la définition de ce qu'est la diaspora indienne avec efficacité, en quatre pages à peine (pp. 3-7), en proposant une définition par l'idéel: en raison de la diversité des situations locales, soulignée, de l'absence avérée de marqueurs identitaires communs (la religion puis la structuration sociale par la caste sont successivement récusées) comme de l'absence de mythe du retour, la diaspora se définirait par "un sens croissant d'appartenance ethnique dans différents pays " (Cohen, 1997) structuré par le biais d'un imaginaire partagé d'une identité et d'une culture « indiennes ». C'est en quelque sorte une définition en creux qui nous est proposée : cette diaspora apparaît certes moins structurée et cohérente que d'autres au plan matériel, mais on ne saurait désigner autrement ce phénomène migratoire et culturel. L'introduction soulève ensuite les enjeux de la mondialisation et des nouveaux flux migratoires, qui d'après l'auteur ne vont qu'approfondir les fractures existantes au sein de la réalité complexe et multiple de la diaspora indienne. Un résumé des contributions clôt cette introduction (pp. 7-12).

Le reste de l'ouvrage est composé de dix chapitres d'une vingtaine de pages chacun qui portent sur des groupes diasporiques définis par leur ancrage national, au Sud (Maurice, Afrique du Sud, Malaisie, Sri Lanka, Trinidad : espaces anciens de peuplement et d'expansion culturelle, et territoires de l'empire britannique concernés par le coolie trade) et au Nord (Australie, États-Unis d'Amérique, Canada, Grande-Bretagne), ainsi qu'un chapitre sur le Golfe. Les dix contributeurs viennent d'horizons disciplinaires et géographiques divers, bien qu'une représentation importante des politistes et des anthropologues rappelle les spécialités des éditeurs.

6 Les approches et thèmes abordés par ces dix chapitres peuvent être répartis en deux groupes. Un certain nombre de contributions s'attachent, souvent de façon brillante, à une réflexion d'ensemble portant sur les populations d'origine indienne de Maurice, Sri Lanka, Trinidad et de Grande-Bretagne (chapitres 1, 4, 6, 10), approfondissant leurs dynamiques internes (en soulignant les éventuelles sous-divisions et lignes de tensions internes fondées sur des origines régionales ou religieuses différentes, des itinéraires migratoires distincts, ou encore des trajectoires socio-économiques diverses), leurs relations avec le reste de la population nationale, et la complexité de la question identitaire et de celle du rapport à l'Inde et à l'Asie du Sud post-Partition. On notera l'intérêt du chapitre 1, qui questionne la construction et l'instrumentalisation de l'image de Petite Inde («Chota Bharat») par l'état mauricien indépendant, dans le 
contexte original d'une population nationale majoritairement d'origine sud-asiatique ; du chapitre 4, marqué par un parti pris déconstructionniste et postcolonial, qui développe une "archéologie " provocatrice de la construction de l'indianité comme Autre au Sri Lanka, au mépris des origines du peuplement de l'île, et des influences et échanges constants avec le continent; de la synthèse de Roger Ballard, analysant les ressorts de la diversité et de la complexité que recouvre les termes de "présence sudasiatique en Grande-Bretagne ", dans une perspective anthropologique véritablement transnationale et multilocale (chapitre 10).

7 Le reste des contributions s'inscrit dans une logique plus descriptive; certains cas étudiés ne sont pas mis en perspective à une échelle autre que communautaire, ou renouvellent peu les études existantes. On en retiendra les chapitres concernant l'Australie et les États-Unis (chapitres 7 et 8). Carmen Voigt-Graf et Johanna Lessinger soulignent l'inscription dans le temps long et à la croisée de flux migratoires très différents, et partant, la complexité de la constitution de ce que l'on voudrait voir dans un contexte anglo-saxon comme une seule et même communauté. Ces chapitres ont le mérite de réexaminer ce que peut recouvrir le terme de diaspora indienne, peut-être limité dans l'esprit des autorités indiennes à l'image trompeuse de la "communauté modèle » des États-Unis (chapitre 8), alors qu'elle est faite de groupes disparates aux histoires et aux logiques radicalement différentes (chapitre 7).

Cet ouvrage est d'un réel intérêt en ce qui concerne la diaspora indienne. Il reflète au final assez bien la diversité des travaux menés sur ce sujet, au travers de contributions dans l'ensemble d'une grande qualité, qui le situent au-dessus de la moyenne des ouvrages disponibles. Toutefois si les enjeux centraux sont bien ciblés par l'introduction, la forme de l'ouvrage rend difficile l'accès aux passages théoriques qui la prolonge dans le corps des contributions. Par ailleurs, un chapitre synthétique portant sur les migrations à partir de l'Inde pré et post-Indépendance/Partition, et sur l'évolution politique sur la question migratoire et à l'égard des émigrés et de la diaspora, eût permis de mieux mettre en perspective les différentes contributions ainsi que le renouveau récent des rapports et échanges entre groupes diasporiques et Inde, relevé de façon convergente par plusieurs auteurs. Ce n'est pas encore l'ouvrage transversal s'inscrivant dans un registre généraliste et théorique, tant attendu, qu'on aurait espéré trouver derrière ce titre et dans cette collection. Cela souligne les obstacles inhérents à une publication de ce type que sont le délai nécessaire à la maturation de cet objet de recherche récent qu'est la diaspora indienne, les difficultés pour faire collaborer des chercheurs dispersés, et le défi de l'ampleur du champ à embrasser, une diaspora couvrant douze à vingt millions d'individus.

\section{AUTEURS}

\section{AURÉLIE VARREL}

Doctorante, Migrinter (CNRS/Université de Poitiers) 